\title{
Does physical appearance perfectionism predict disordered dieting?
}

\author{
Diana Czepiel $^{1}$ (D) Hendricus M. Koopman ${ }^{1}$ \\ Accepted: 16 December 2020 / Published online: 26 January 2021 \\ (C) The Author(s) 2021
}

\begin{abstract}
Despite that disordered eating has been repeatedly associated with perfectionism, the results are inconsistent as to which exact dimensions of perfectionism it is related to. Moreover, the increasing evidence that perfectionism is best conceptualized as a domain-specific, as opposed to a global, trait contribute to the lack of clarity. Therefore, the aim of this study was to examine which dimensions of global and physical appearance perfectionism statistically predict disordered dieting in a non-clinical adult female sample. In total 437 participants completed the Short Almost Perfect Scale, which distinguishes between adaptive and maladaptive perfectionism, the Physical Appearance Perfectionism Scale, which distinguishes between hope for perfection and worry about imperfection, and the Dieting subscale of the Eating Attitudes Test-26. A hierarchical regression analysis revealed that only maladaptive, as opposed to adaptive, global perfectionism statistically predicted disordered dieting. Furthermore, both dimensions of physical appearance perfectionism statistically predicted disordered dieting, although worry about imperfection, its maladaptive dimension, was the strongest statistical predictor. The present results demonstrate that worry about imperfection is an effective statistical predictor of disordered dieting among women, possibly serving as a starting point for further research investigating the utility of its incorporation in prevention and treatment protocols for disordered eating.
\end{abstract}

Keywords Global perfectionism · Domain-specific perfectionism · Physical appearance perfectionism · Dieting $\cdot$ Disordered eating

\section{Introduction}

Despite the lack of consensus regarding the definition of perfectionism, most researchers agree that it "involves high standards of performance which are accompanied by tendencies for overly critical evaluations of one's behavior" (Frost, Marten, Lahart, \& Rosenblate, 1990, p. 450) and that it is best conceptualized as multidimensional. Some authors suggest the existence of various negative and positive dimensions (dimensional model; Frost et al., 1990; Hewitt \& Flett, 1991), whereas others suggest a categorical model, consisting of two distinct categories of perfectionism (Mitzman, Slade, \& Dewey, 1994; Slaney, Rice, Mobley, Trippi, \& Ashby, 2001;

The current manuscript has been based on an academic thesis published by Leiden University (https://openaccess.leidenuniv.nl/handle/1887/ 60288).

Diana Czepiel

czepiel.diana@gmail.com

1 Department of Clinical Psychology, Faculty of Social Sciences, Leiden University, Wassenaarseweg 52, P.O. Box 9555, 2300, RB Leiden, The Netherlands
Stumpf \& Parker, 2000; Terry-Short, Owens, Slade, \& Dewey, 1995). Another approach to the conceptualization of perfectionism is the concept of perfectionistic self-presentation, which "focuses on the expression of one's supposed perfection to others", as opposed to trait perfectionism, namely the dimensional and categorical model, which "focuses on motives and dispositions related to attaining perfectionism" (Sherry, Hewitt, Flett, Lee-Baggley, \& Hall, 2007, p. 478). Maladaptive perfectionism has been proven to be central in the development, maintenance and course of numerous disorders, such as depression, obsessive-compulsive disorder, social anxiety, obsessive-compulsive personality disorder (Egan, Wade, \& Shafran, 2011; Shafran \& Mansell, 2001), as well as eating disorders (for a review see Bardone-Cone et al., 2007; Farstad, McGeown, \& Von Ranson, 2016; Jacobi, Hayward, de Zwaan, Kraemer, \& Agras, 2004; Stice, 2002).

\section{Perfectionism and Disordered Eating}

Beside eating disorders, there is a well-established relationship between perfectionism and disordered eating. The latter consists of a broad range of "abnormal behaviors associated with eating disorders" (Quick, Byrd-Bredbenner, \& Neumark- 
Sztainer, 2013, p. 278), which do not fulfil the criteria for a clinical diagnosis. Disordered eating usually involves behaviors such as restraint eating, emotional eating, disinhibited eating, night eating, binge-eating, strict dieting and controlling one's body weight and shape through inappropriate compensatory behaviors (e.g., purging), as well as weight, shape, and eating concerns (Quick et al., 2013). Such symptoms warrant both investigative and clinical attention, considering that, according to the continuum perspective, individuals with disordered eating often present the same disordered-eating behaviors and attitudes as patients suffering from an eating disorder, but in a less severe and/or frequent manner (Cooley \& Toray, 2001; Fitzgibbon, Sánchez-Johnsen, \& Martinovich, 2003; Peck \& Lightsey, 2008). Disordered eating warrants attention also because it often precedes the development of an eating disorder (Nevonen \& Broberg, 2000; Polivy \& Herman, 1985), increases the risk of developing a (sub)threshold eating disorder (Keel, Heatherton, Baxter, \& Joiner, 2007; Polivy \& Herman, 1985; Rojo et al., 2003; Stice, Ng, \& Shaw, 2010), as well as because its prevalence among adult women is at least twice as high compared to eating disorders (Drewnowski, Yee, Kurth, \& Krahn, 1994; Shisslak, Crago, \& Estes, 1995).

Despite that there is an extensive literature regarding the relationship between perfectionism and disordered eating, findings are inconsistent to some extent. Some studies adopting the dimensional approach conclude that disordered eating is associated with both adaptive and maladaptive dimensions of perfectionism (Downey, Reinking, Gibson, Cloud, \& Chang, 2014; Esposito, Stoeber, Damian, Alessandri, \& Lombardo, 2019; Macedo et al., 2007; Muyan, Chang, Jilani, \& Yu, 2015; Stoeber \& Yang, 2015; Welch, Miller, Ghaderi, \& Vaillancourt, 2009), other papers reach the conclusion that it is associated only with adaptive dimensions of perfectionism (Joyce, Watson, Egan, \& Kane, 2012; Lethbridge, Watson, Egan, Street, \& Nathan, 2011; Luo, Forbush, Williamson, Markon, \& Pollack, 2013), whereas according to other studies disordered eating is exclusively associated with maladaptive dimensions of perfectionism (Shafran, Lee, Payne, \& Fairburn, 2006; Sherry et al., 2009). Research adopting the categorical approach to measuring perfectionism has yielded somewhat more consistent results, suggesting that only maladaptive perfectionism is associated with disordered eating (Choo \& Chan, 2013; Dour \& Theran, 2011; Haase, Prapavessis, \& Owens, 2002; Holston \& Cashwell, 2000; Patterson, Wang, \& Slaney, 2012; Paulson \& Rutledge, 2014; Pearson \& Gleaves, 2006). Other studies that made use of the categorical approach, however, found that groups demonstrating both adaptive and maladaptive perfectionism scored high on disordered eating measures (Haynos et al., 2018a; Slof-Op't Landt, Claes, \& van Furth, 2016), although lower than the merely maladaptive perfectionism group (Haynos et al., 2018a). This lack of consistence may be attributed to the existence of numerous behaviors indicative of disordered eating that are often significantly different in nature (e.g. strict dieting differs significantly from bulimic symptoms in terms of etiology and treatment). Another possible explanation for the inconsistent findings might be the use of different scales for the measurement of disordered eating and perfectionism, which seem to capture different aspects of these variables. In fact, Welch et al. (2009) claimed that the relationship between perfectionism and disordered eating seems to differ depending on the used tests. For instance, the same dimensions of perfectionism measured by different instruments (Eating Disorder Inventory- Perfectionism subscale and Hewitt Multidimensional Perfectionism Scale) were correlated with the subscales of the Eating Attitudes Test in one study (Sherry, Hewitt, Besser, McGee, \& Flett, 2004) but not in another (Hewitt, Flett, \& Ediger, 1995).

Consequently, in the current study it was decided to focus on dieting for the purposes of clarity. Even though dieting can be viewed as salutary-when healthy changes in one's diet in order to lose weight are considered-it can be also deemed as morbid when taking the form of unhealthy weight-control behaviors, such as severe caloric restriction or fasting (Brownell \& Rodin, 1994). In the latter case, dieting behavior is often accompanied by a dieting mindset, such as shape and weight concerns (Lowe, as cited in Brownell \& Rodin, 1994). To reflect the unhealthy aspect of dieting, the term disordered dieting was selected. Among the various disordered eating behaviors, disordered dieting was selected because of its high prevalence across the lifespan. More specifically, the reported prevalence of dieting among adult women ranges between $27 \%$ and $68 \%$ (Hetherington \& Burnett, 1994; Liechty \& Lee, 2013; Mangweth-Matzek et al., 2006; Slof-Op't Landt et al., 2017). In other studies it has been found that $10 \%$ to $58 \%$ of adult women engage in disordered dieting (Haynos, Wang, \& Fruzzetti, 2018b; Krahn, Kurth, Gomberg, \& Drewnowski, 2005; Mangweth-Matzek et al., 2006; Neumark-Sztainer et al., 2006). In addition, disordered dieting is associated with various negative psychological outcomes, such as substance use (Brown, Kola-Palmer, \& Dhingra, 2015; Crow, Eisenberg, Story, \& Neumark-Sztainer, 2006; Krahn et al., 2005), suicidal ideation (Brown et al., 2015), affect regulation problems (Ackard, Croll, \& KearneyCooke, 2002; Haynos et al., 2018a), body dissatisfaction (Crow et al., 2006), depression, as well as low self-esteem (Ackard et al., 2002; Crow et al., 2006). It has been also found that disordered dieting is a risk factor for the onset of eating disorders (Neumark-Sztainer et al., 2006; Rojo et al., 2003; Stice, Marti, \& Durant, 2011).

\section{Domain-Specific Perfectionism}

An increasing number of studies demonstrates that perfectionists usually do not hold high personal standards across all domains, but only in certain domains (Levine \& 
Milyavskaya, 2018)-usually in the ones they value the most (Mitchelson, 2009; Murphy, Straebler, Cooper, \& Fairburn, 2010; Shafran, Cooper, \& Fairburn, 2002). One of the domains in which individuals often exhibit perfectionism is physical appearance (Haase, Prapavessis, \& Owens, 2013; Stoeber \& Stoeber, 2009). Similarly to global perfectionism, domain-specific perfectionism is multidimensional in nature (Haase et al., 2013). This also applies to physical appearance perfectionism (PAP), which consists of a maladaptive dimension (worry about imperfection) and a (mostly) adaptive dimension (hope for perfection; Yang \& Stoeber, 2012). Moreover, in accordance with research which suggests that context-specific, compared to global, measures of psychological variables are characterized by higher predictive power and provide a greater magnitude of the examined relationships (Bing, Whanger, Davison, \& VanHook, 2004; Hunthausen, Truxillo, Bauer, \& Hammer, 2003), domain-specific perfectionism is believed to predict an individual's performance in the given domain more effectively. For instance, it has been found that PAP predicts disordered eating above global perfectionism among female university students (Bergunde \& Dritschel, 2020; Stoeber \& Yang, 2015). PAP has been associated with disordered eating also in other studies. Specifically, it has been reported that its maladaptive dimension is positively correlated with restrained eating and physical appearance concerns (Yang \& Stoeber, 2012), whereas perfectionism in the weight/shape domain is correlated with dieting and binge-eating (Cain, Bardone-Cone, Abramson, Vohs, \& Joiner, 2008). Furthermore, Shafran et al. (2002) argued that eating disorders constitute the "expression of perfectionism in the domain of eating, shape or weight and their control" (p. 783-784), whereas Macedo et al. (2007) suggested that perfectionism in the domain of body image or weight may increase the risk of disordered eating and eating disorders. Finally, according to qualitative research conducted among patients with an eating disorder, some-but not allmentioned striving for a perfect physical appearance as the reason for developing an eating disorder (Petersson, Johnsson, \& Perseius, 2017).

\section{The Present Study}

Taking all the above into consideration, the current study aimed to examine which dimensions of global perfectionism and PAP statistically predict disordered dieting most effectively among women. Despite the existence of some relatively consistent associations between disordered eating and maladaptive (dimensions of) perfectionism, there are also some studies linking disordered eating to adaptive (aspects of) perfectionism. The first goal of the study, therefore, was to examine whether disordered dieting is statistically predicted only by maladaptive or also by adaptive global perfectionism, as conceptualized by the categorical model. Moreover, bearing in mind the suggestions that domain-specific perfectionism is more effective than global perfectionism in predicting an individual's performance in the given domain, it is anticipated that PAP and particularly its maladaptive dimension (worry about imperfection) will statistically predict disordered dieting above global perfectionism. Nevertheless, given that disordered eating has been associated also with positive aspects of perfectionism, the adaptive dimension of PAP (hope for perfection) will be also examined as a predictor. This knowledge will provide valuable directions for future research, with the aim of developing effective prevention programs and improved treatment protocols for disordered eating by targeting the appropriate dimensions of perfectionism.

\section{Methods}

\section{Participants}

A total of 437 women aged between 18 and 65 participated in the study, with an average age of $29.23(S D=8.90)$. The average Body Mass Index (BMI) was $23.40(S D=5.14)$, which falls within the range of normal weight (18.5-25). The majority was (self-)employed (38.2\%) or a student $(30.7 \%)$, whereas the remaining $31.1 \%$ was a working student, out of work, a homemaker, retired or unable to work. Regarding the participants' relationship status, more than half was single/ never married $(56.8 \%)$, followed by being married/ in a domestic partnership (40.3\%), whereas the remaining $2.9 \%$ was divorced, separated or widowed. Finally, most participants had completed a master's degree $(42.8 \%)$ or a bachelor's degree $(38.7 \%)$, whereas the remaining $18.5 \%$ had completed a doctorate degree, high school, technical/ vocational training or no schooling.

\section{Procedure}

Online questionnaires using Google forms were administered to female community members in the Netherlands, forwarded via various groups on social media. Participants completed the questionnaires on a voluntary basis without any compensation in exchange. They were asked to provide consent after being informed about their rights, as well as after being assured of the confidentiality of the process and the anonymity of their data.

\section{Measures}

\section{Global Perfectionism}

The Short Almost Perfect Scale (SAPS; Rice, Richardson, \& Tueller, 2014) is an 8-item self-report instrument assessing perfectionism according to the categorical model. It consists 
of two subscales: Standards (4 items; e.g. "I have high expectations for myself") and Discrepancy (4 items; e.g. "My performance rarely measures up to my standards"). Standards refer to setting high standards for one's performance and are considered to reflect positive aspects of perfectionism, whereas Discrepancy refers to the divergence between one's expectations and one's actual performance, reflecting thus negative aspects of perfectionism. Each item is rated on a seven-point Likert scale ranging from 1 (strongly disagree) to 7 (strongly agree). The participants' score on Standards distinguishes perfectionists (high score) from non-perfectionists (low score), whereas their score on Discrepancy distinguishes adaptive perfectionists (low score) from maladaptive perfectionists (high score). Reported Cronbach alpha's range from .85 to .87 for Standards and .84 to .87 for Discrepancy.

\section{Physical Appearance Perfectionism}

The Physical Appearance Perfectionism Scale (PAPS; Yang $\&$ Stoeber, 2012) is a 12-item self-report questionnaire that assesses multidimensional physical appearance perfectionism. It consists of two subscales: Worry about imperfection (7 items; e.g. "I am not satisfied with my appearance"), which pertains to worrying that one's appearance is imperfect and is considered maladaptive, and Hope for perfection ( 5 items; e.g. "I hope others admire my appearance"), which pertains to hoping for a perfect appearance and is considered positive for the most part. The items are rated on a five-point Likert scale ranging from 1 (strongly disagree) to 5 (strongly agree). The reported reliability for Worry about imperfection is $\alpha=.85$, whereas for Hope for perfection it is $\alpha=.80$.

\section{Disordered Dieting}

The Eating Attitudes Test-26 (EAT-26; Garner, Olmsted, Bohr, \& Garfinkel, 1982) is a self-report questionnaire that is considered "useful in identifying a group with abnormal concerns with eating and weight" (p. 871) in non-clinical samples. It is worth noting that high scores are merely indicative of abnormal eating patterns and are not suggestive of a diagnosis. The Dieting subscale consists of 13 items, reflecting preoccupations about one's shape and a pathological tendency to avoid foods that are fattening (e.g. "I am terrified about being overweight", "I avoid foods with sugar in them"). Each item is rated on a six-point Likert scale ranging from 1 (always) to 6 (never), which is later recoded as following: always $=3$, usually $=2$, often $=1$, sometimes, rarely or never $=0$. Its reported reliability is $\alpha=.90$.

\section{Statistical Analysis}

The assumption of normality was violated, therefore nonparametric tests were used where applicable and medians are reported. In addition, the assumptions of homoscedasticity, linearity and normality of residuals were violated, thus $95 \%$ bias corrected and accelerated bootstrap confidence intervals and standard errors are reported. Participants' BMI was calculated based on self-reported height and weight $\left(\mathrm{kg} / \mathrm{m}^{2}\right)$.

Following the recommendations of prior research (Gilman \& Ashby, 2003; Rice \& Ashby, 2007; Rice, Ashby, \& Gilman, 2011), participants were classified into three categories of global perfectionism by conducting a two-step cluster analysis. First, a hierarchical cluster analysis was performed using the Ward's linkage method and the squared Euclidian distance measure. The obtained agglomeration schedule was examined by calculating the percentage of increase in the agglomeration coefficients at each step from bottom up (Pastor, 2010). Next, based on the cluster centroids that emerged from the hierarchical cluster analysis, a k-means cluster analysis was performed. In order to recognize the three clusters, the participants' mean scores were examined. According to the literature (Rice et al., 2011; Rice \& Ashby, 2007), the cluster with a high score on Standards and a low score on Discrepancy was considered to represent adaptive perfectionists, the cluster with a high score on both Standards and Discrepancy was considered to represent maladaptive perfectionists, whereas the cluster with a low score on Standards was considered to represent non-perfectionists. PAP, on the other hand, was handled dimensionally following the recommendations of the scale developers. The findings should be, thus, treated with caution, considering that dimensional variables generally preserve greater power in a regression model than categorical variables.

Subsequently, with the aim of answering the research questions and hypothesis, a hierarchical multiple regression was performed, with disordered dieting as the dependent variable. After centering the continuous variables and dummy coding the categorical variable, age and BMI were entered as predictors in the first step, so that they could be statistically controlled for. In the second step the two categories of global perfectionism (adaptive and maladaptive perfectionism) were simultaneously entered as predictors, whereas in the third step worry about imperfection and hope for perfection were simultaneously entered as predictors. Analyses were conducted on SPSS version 23; an alpha level of .05 was used for all statistical tests.

\section{Results}

\section{Descriptive Statistics}

The descriptive statistics regarding the participants' scores on the main study variables are presented in Table 1, along with the coefficient alpha reliabilities. Spearman's ranked-order correlation coefficients showed that there were statistically 
Table 1 Descriptive Statistics for SAPS, PAPS and the Dieting Subscale of EAT-26

\begin{tabular}{llllll}
\hline & $\alpha$ & $M$ & $S D$ & Mdn & Min \\
\hline SAPS- Standards & .82 & 22.29 & 4.23 & 23.00 & 4 \\
SAPS- Discrepancy & .86 & 16.50 & 6.14 & 16 & 28 \\
PAPS- Hope for perfection & .85 & 17.39 & 4.24 & 18 & 4 \\
PAPS-Worry about imperfection & .91 & 18.99 & 7.21 & 18 & 5 \\
EAT-26- Dieting & .88 & 8.74 & 7.91 & 7 & 7 \\
\hline
\end{tabular}

SAPS = Short Almost Perfect Scale; PAPS = Physical Appearance Perfectionism Scale; EAT-26 = Eating Attitudes Test-26

significant intercorrelations among the majority of the study variables, as it can be seen in Table 2.

\section{Classification by Type of Global Perfectionism}

The agglomeration schedule provided support for a threecluster solution, given that there was a large increase in coefficients $(61 \%)$ moving from a two- to a one-cluster solution and a large increase in coefficients (59\%) moving from a three- to a two-cluster solution, whereas moving from a four- to a three-cluster solution a small increase was noted $(27 \%)$. The k-means analysis for the three-cluster solution converged in six iterations. Means and standard deviations by perfectionist type are shown in Table 3.

\section{Perfectionism and Disordered Dieting}

In the first step, age and BMI explained $2.5 \%$ of the variance, $F(2,434)=5.45, p=.005, R^{2}=.025$, both of which uniquely predicted disordered dieting, $\beta=-.11, \mathrm{t}=-2.14, p=.033$ and $\beta=.14, t=2.96, p=.003$ respectively. Maladaptive and adaptive perfectionism, which were added in the second step, significantly contributed to the regression model by explaining an additional $2.8 \%$ of the variance, $F(4,432)=5.95, p<.001$, $R^{2}=.052$. In the second step age was no longer a significant predictor, whereas BMI uniquely contributed to the prediction of disordered eating, $\beta=.13, \mathrm{t}=2.74, p=.006$. In this step, adaptive perfectionism did not uniquely predict disordered dieting, whereas maladaptive perfectionism did, $\beta=.16, t=$ $2.67, p=.008$. The addition of worry about imperfection and hope for perfection in the third step explained an additional $11.7 \%$ of the variance, $F(6,430)=14.62, p<.001, R^{2}=.169$. In this step, BMI and maladaptive perfectionism were no longer significant predictors. Hope for perfection uniquely contributed to the prediction of disordered dieting, $\beta=.10, t=$ $2.00, p=.046$, whereas worry about imperfection emerged as the strongest statistical predictor of disordered dieting, $\beta=.33, t=6.07, p<.001$. The results of the hierarchical regression analysis are presented in Table 4.

\section{Discussion}

The goal of the current study was to examine which dimensions of global perfectionism and PAP statistically predict disordered dieting most effectively in a non-clinical sample of women. With regard to the first research question, it was found that only maladaptive, as opposed to adaptive, global perfectionism statistically predicted disordered dieting. This finding corroborates previous literature that has consistently linked maladaptive (dimensions of) perfectionism to disordered eating as reviewed in the introduction, whereas it does not support studies that have revealed a positive relationship between disordered eating and adaptive dimensions of
Table 2 Intercorrelations among SAPS, PAPS, the Dieting Subscale of EAT-26, BMI and Age

\begin{tabular}{lllllll}
\hline & 1 & 2 & 3 & 4 & 5 & 6 \\
\hline 1. SAPS- Standards & - & & & & & \\
2. SAPS- Discrepancy & $.33^{* *}$ & - & & & & \\
3. PAPS- Hope for perfection & $.17^{* *}$ & $.19^{* *}$ & - & & & \\
4. PAPS- Worry about imperfection & .08 & $.46^{* *}$ & $.38^{* *}$ & - & & \\
5. EAT-26- Dieting & .08 & $.19^{* *}$ & $.27^{* *}$ & $.42^{* *}$ & - & \\
6. BMI & .04 & .02 & -.07 & $.28^{* *}$ & $.23^{* *}$ & - \\
7. Age & -.05 & -.07 & $-.26^{* *}$ & $-.10^{*}$ & -.05 & $.28^{* *}$ \\
\hline
\end{tabular}

SAPS $=$ Short Almost Perfect Scale; PAPS $=$ Physical Appearance Perfectionism Scale; EAT-26= Eating Attitudes Test-26; BMI = Body Mass Index

$* p<.005 . * * p<.001$ 
Table 3 Means (M) and Standard Deviations (SD) by Perfectionist Type

\begin{tabular}{|c|c|c|c|c|c|c|c|}
\hline \multirow[t]{2}{*}{ SAPS subscales } & \multicolumn{2}{|c|}{$\begin{array}{l}\text { Adaptive perfectionists } \\
n=148(33.9 \%)\end{array}$} & \multicolumn{2}{|c|}{$\begin{array}{l}\text { Maladaptive } \\
\text { perfectionists } n=186 \\
(42.6 \%)\end{array}$} & \multicolumn{2}{|c|}{$\begin{array}{l}\text { Non-perfectionists } \\
n=103(23.6 \%)\end{array}$} & \multirow[b]{2}{*}{$F(2,434)$} \\
\hline & $M$ & $S D$ & $M$ & $S D$ & $M$ & $S D$ & \\
\hline Standards & $23.77_{\mathrm{a}}$ & 2.21 & $24.49_{\mathrm{b}}$ & 2.40 & $16.19_{\mathrm{c}}$ & 3.10 & $397.09^{*}$ \\
\hline Discrepancy & $11.58_{\mathrm{a}}$ & 3.19 & $22.29 \mathrm{~b}$ & 3.17 & $13.10_{\mathrm{c}}$ & 4.50 & $441.50^{*}$ \\
\hline
\end{tabular}

Means not sharing the same subscript are significantly different at $p<.001$ according to post hoc Bonferroni corrections. SAPS $=$ Short Almost Perfect Scale perfectionism (e.g. Joyce et al., 2012; Lethbridge et al., 2011; Luo et al., 2013). Individuals who demonstrate maladaptive perfectionism set high standards for themselves, which they believe that they fail to reach, leading them to engage in harsh self-criticism (Enns \& Cox, 2002). Therefore, they may restrict their diet as a way of exerting control over their body (Fairburn, Shafran, \& Cooper, 1999; Slade, 1982) and consequently over at least one domain of their life (Cain et al., 2008; Haase et al., 2002; Murphy et al., 2010; Schmidt \& Treasure, 2006; Slade, 1982; Soenens et al., 2008), which provides them

Table 4 Summary of Hierarchical Multiple Regression Model for Variables Predicting Disordered Dieting

\begin{tabular}{|c|c|c|c|c|}
\hline & \multicolumn{4}{|c|}{ Model summary } \\
\hline & $R^{2}$ & $\Delta R^{2}$ & $F$ & $\Delta F$ \\
\hline Step 1 & .025 & .025 & $5.45^{*}$ & $5.45 *$ \\
\hline Step 2 & .052 & .028 & $5.95 * *$ & $6.31 *$ \\
\hline \multirow[t]{2}{*}{ Step 3} & .169 & .117 & $14.62 * *$ & $30.34 * *$ \\
\hline & \multicolumn{4}{|c|}{ Individual predictors } \\
\hline Predictors & B & SE B & $\beta$ & $95 \% \mathrm{CI}$ \\
\hline \multicolumn{5}{|l|}{ Step 1} \\
\hline Age & -0.09 & 0.04 & $-.11^{*}$ & {$[-0.17,-0.01]$} \\
\hline BMI & 0.22 & 0.09 & $.14^{*}$ & {$[0.07,0.42]$} \\
\hline \multicolumn{5}{|l|}{ Step 2} \\
\hline Age & -0.09 & 0.04 & -.10 & {$[-0.17,0.00]$} \\
\hline BMI & 0.20 & 0.09 & $.13^{*}$ & {$[0.04,0.41]$} \\
\hline Maladaptive perfectionism & 2.55 & 1.00 & $.16^{*}$ & {$[0.57,4.48]$} \\
\hline Adaptive perfectionism & -0.20 & 0.93 & -.01 & {$[-2.02,1.82]$} \\
\hline \multicolumn{5}{|l|}{ Step 3} \\
\hline Age & -0.03 & 0.04 & -.03 & {$[-0.11,0.06]$} \\
\hline BMI & 0.08 & 0.07 & .05 & {$[-0.05,0.24]$} \\
\hline Maladaptive perfectionism & 0.80 & 0.95 & .05 & {$[-1.15,2.69]$} \\
\hline Adaptive perfectionism & 0.14 & 0.87 & .01 & {$[-1.57,1.94]$} \\
\hline Worry about imperfection & 0.36 & 0.06 & $.33 * *$ & {$[0.24,0.47]$} \\
\hline Hope for perfection & 0.19 & 0.09 & $.10 *$ & {$[0.01,0.36]$} \\
\hline
\end{tabular}

Confidence intervals and standard errors are based on 1000 bootstrap samples. BMI $=$ Body Mass Index

$* p<.05$. ** $p<.001$ with a sense of achievement (Fairburn et al., 1999; Schmidt \& Treasure, 2006). Moreover, people who present disordered eating tend to engage in all-or-nothing thinking (Bauer \& Anderson, 1989; Schmidt \& Treasure, 2006; Shafran et al., 2002; Slade, 1982), while setting extremely high standards with regard to their performance, physical appearance and/or eating habits (Fairburn, Cooper, \& Shafran, 2003; Shafran et al., 2002). The unrealistic nature of such standards combined with all-or-nothing thinking, renders it more likely for them to believe that they have failed to live up to their expectations (Fairburn et al., 2003; Hewitt et al., 1995), causing them to experience discrepancy, and thus to demonstrate maladaptive perfectionism.

The research hypothesis that PAP, and specifically worry about imperfection, would predict disordered dieting above global perfectionism was confirmed, substantiating studies in which domain-specific perfectionism statistically predicted various body-image aspects (Dunn, Gotwals, \& Dunn, 2005) and disordered eating (Bergunde \& Dritschel, 2020; Stoeber \& Yang, 2015) above global perfectionism. The present results extend these studies by showing that worry about imperfection predicts disordered dieting in particular above global perfectionism. They also extend them by demonstrating a relationship in a community sample, as opposed to a university sample. This is of interest, considering that disordered eating in middle-aged and elderly women is not only present, but is also related to perfectionism (Midlarsky, Marotta, Pirutinsky, Morin, \& McGowan, 2018; Midlarsky \& Nitzburg, 2008; Thompson \& Bardone-Cone, 2019). Moreover, the current results provide support to previous literature that links perfectionism in the domain of physical appearance to various aspects of disordered eating and eating disorders (Heatherton \& Baumeister, 1991; Shafran et al., 2002; Yang \& Stoeber, 2012).

A possible explanation for the relationship between worry about imperfection and disordered dieting could be that those demonstrating maladaptive PAP, similarly to maladaptive perfectionists, exhibit concerns revolving mainly around worry about mistakes and imperfection (Enns \& Cox, 2002). In response to these concerns they may restrict their diet or adopt rigid eating behaviors in order to make up for their 
imperfections and to ensure that they reach their ideal weight or shape (Verstuyf, Patrick, Vansteenkiste, \& Teixeira, 2012), engaging thus in disordered dieting. Furthermore, individuals manifesting disordered eating are considerably preoccupied with eating, their weight and their shape (American Psychiatric Association, 2013; Fairburn et al., 2003; Murphy et al., 2010; Slade, 1982), whereas their self-worth is largely or exclusively dependent on their control over these aspects (American Psychiatric Association, 2013; Fairburn et al., 2003; Murphy et al., 2010; Shafran et al., 2002). Considering that failure in the domain of physical appearance would pose a threat to their self-esteem, they may strive for excellence in that specific domain (Crocker \& Knight, 2005; Crocker, Luhtanen, Cooper, \& Bouvrette, 2003), manifesting perfectionism, in this case PAP.

Despite that worry about imperfection emerged as the strongest statistical predictor, hope for perfection also statistically predicted disordered dieting. It appears, therefore, that even hoping to attain a perfect physical appearance might make individuals prone to engage in strict dieting behaviors with the aim of making their hope come true. This result does not come as a complete surprise, given that the creators of the PAPS suggest that hope for perfection also seems to capture some negative aspects of PAP, since it is correlated with body image disturbances regarding body shape and appearance, although to a lesser extent than worry about imperfection (Yang $\&$ Stoeber, 2012). Bergunde and Dritschel (2020) propose that hope fails to capture the aspect of actively straining to achieve one's perfectionistic standards-as opposed to passive wishes for perfection-and therefore modified the PAPS by replacing the term hope with strive, which resulted in improved differential construct validity.

The current finding confirms the study by Bergunde and Dritschel (2020), but contradicts the study by Stoeber and Yang (2015), who found that only worry about imperfection predicted disordered eating. This inconsistency might be attributed to the fact that the concept of disordered eating in the later study captured drive for thinness, bulimia and body dissatisfaction as one total score. Bearing in mind the significantly diverse nature of disordered eating symptoms, it is possible that combining them in one general score blurred their exact relationship with the dimensions of PAP. Disordered dieting in particular might present a different association with PAP compared to other disordered eating behaviors and attitudes, being statistically predicted not only by its maladaptive, but also by its (mainly) adaptive dimension.

Stoeber, Madigan, Damian, Esposito, and Lombardo (2017) concluded that perfectionistic self-presentation explained the relationship they found between perfectionism and disordered dieting. In this context, it is likely that individuals hoping to have a perfect physical appearance engage in disordered dieting because of a desire to promote a perfect (physical) image to others. Other studies suggest that (one of) the main incentive(s) for dieting among normal-weight adolescent girls and women is improving one's appearance (Berman, 1975; Dwyer, Feldman, \& Mayer, 1970; Martinsen, Bratland-Sanda, Eriksson, \& Sundgot-Borgen, 2010). It can be, thus, suggested that disordered dieting constitutes a means of attaining the perfect physical appearance they hope for. Finally, a reasonable explanation for the fact that worry about imperfection was a stronger statistical predictor than hope for perfection may be the theory of approach and avoidance motivation, according to which a behavior is either motivated by achieving a positive stimulus or by avoiding a negative stimulus (Elliot, 2008). Likewise, dieting can be considered a way of either attaining the hoped-for body and appearance or distancing oneself from a feared body and appearance. Considering that a feared body has greater impact on individuals than a hoped-for body (Dalley \& Buunk, 2011), it may be speculated that worry about imperfection in one's physical appearance is a stronger motive to engage in disordered dieting than hoping for perfection.

\section{Clinical Implications}

The higher predictive validity of PAP that was demonstrated in the current study might suggest that the existing prevention programs and treatment protocols should target PAP in order to maximize the effectiveness of the interventions. More specifically, randomized controlled trials could be conducted in order to examine whether modifying primarily this aspect of individuals' perfectionism-instead of seeking to lower their high standards per se-as well as whether capitalizing on the advantages of one's adaptive perfectionism, result in a more successful treatment of eating disorders and disordered eating.

\section{Limitations}

The present study should be considered in light of its limitations. Self-report bias is inherent to this study, as well as the study design was cross-sectional, therefore the timeline cannot be established and causal inferences cannot be made. In addition, among a wide range of disordered eating symptoms, only disordered dieting was studied, whereas the classification of perfectionists as adaptive or maladaptive was performed exclusively on the basis of statistical analysis. Also, the mechanisms that were suggested as explanations of the current findings are assumptions based on literature, whereas the study was conducted exclusively with female participants, who were recruited through convenience sampling. Furthermore, participants were not asked about their race and ethnicity, nor their sexual orientation/gender identity, what may limit the generalizability of the current results. Future research could include a replication of the current study in a clinical population, longitudinal studies in order to establish the timeline between the studied variables, as well as studies investigating 
the underlying mechanisms. Moreover, future studies could include the investigation of different aspects of disordered eating, participants of both genders, as well as interviews or measures filled out by the participant's family and friends in addition to self-report measures. It is also recommended that sexual orientation/ gender identity, as well as race and ethnicity are examined as moderating variables. Finally, the addition of measures investigating the presence of comorbid psychopathology or psychological distress could aid in a more accurate classification of perfectionists.

\section{Conclusion}

In conclusion, the current study demonstrated that only maladaptive, as opposed to adaptive, global perfectionism statistically predicted disordered dieting. Moreover, it provided evidence in support of the higher predictive validity of PAP compared to global perfectionism in the context of disordered dieting. In particular, disordered dieting was statistically predicted by both hope for perfection and worry about imperfection, although the latter was the most effective statistical predictor, encouraging thus further research for the development of relevant treatment and prevention programs.

Availability of Data and Material The datasets generated during and/or analyzed during the current study are available from the corresponding author on reasonable request.

Funding The study received no funding.

\section{Compliance with Ethical Standards}

Conflicts of Interest/Competing Interests The authors declare that they have no conflict of interest.

Ethics Approval Approval was obtained from the ethics committee of Leiden University. The procedures used in this study adhere to the tenets of the Declaration of Helsinki.

Consent to Participate Informed consent was obtained from all participants included in the study.

Consent for Publication Not applicable.

Code Availability Not applicable.

Conflict of Interest On behalf of all authors, the corresponding author states that there is no conflict of interest.

Open Access This article is licensed under a Creative Commons Attribution 4.0 International License, which permits use, sharing, adaptation, distribution and reproduction in any medium or format, as long as you give appropriate credit to the original author(s) and the source, provide a link to the Creative Commons licence, and indicate if changes were made. The images or other third party material in this article are included in the article's Creative Commons licence, unless indicated otherwise in a credit line to the material. If material is not included in the article's
Creative Commons licence and your intended use is not permitted by statutory regulation or exceeds the permitted use, you will need to obtain permission directly from the copyright holder. To view a copy of this licence, visit http://creativecommons.org/licenses/by/4.0/.

\section{References}

Ackard, D. M., Croll, J. K., \& Kearney-Cooke, A. (2002). Dieting frequency among college females: Association with disordered eating, body image, and related psychological problems. Journal of Psychosomatic Research, 52(3), 129-136. https://doi.org/10.1016/ S0022-3999(01)00269-0.

American Psychiatric Association. (2013). Diagnostic and statistical manual of mental disorders (5th ed.). Arlington, VA: American Psychiatric Publishing.

Bardone-Cone, A. M., Wonderlich, S. A., Frost, R. O., Bulik, C. M., Mitchell, J. E., Uppala, S., \& Simonich, H. (2007). Perfectionism and eating disorders: Current status and future directions. Clinical Psychology Review, 27(3), 384-405. https://doi.org/10.1016/j.cpr. 2006.12.005.

Bauer, B. G., \& Anderson, W. P. (1989). Bulimic beliefs: Food for thought. Journal of Counseling \& Development, 67(7), 416-419. https://doi.org/10.1002/j.1556-6676.1989.tb02105.x.

Bergunde, L., \& Dritschel, B. (2020). The shield of self-compassion: A buffer against disordered eating risk from physical appearance perfectionism. PLoS One, 15(1), e0227564. https://doi.org/10.1371/ journal.pone.0227564.

Berman, E. M. (1975). Factors influencing motivations in dieting. Journal of Nutrition Education, 7(4), 155-159. https://doi.org/10. 1016/S0022-3182(75)80010-0.

Bing, M. N., Whanger, J. C., Davison, H. K., \& VanHook, J. B. (2004). Incremental validity of the frame-of-reference effect in personality scale scores: A replication and extension. Journal of Applied Psychology, 89(1), 150-157. https://doi.org/10.1037/0021-9010. 89.1.150.

Brown, C. S., Kola-Palmer, S., \& Dhingra, K. (2015). Gender differences and correlates of extreme dieting behaviours in US adolescents. Journal of Health Psychology, 20(5), 569-579. https://doi.org/10. 1177/1359105315573441.

Brownell, K. D., \& Rodin, J. (1994). The dieting maelstrom: Is it possible and advisable to lose weight? American Psychologist, 49(9), 781791. https://doi.org/10.1037/0003-066X.49.9.781.

Cain, A. S., Bardone-Cone, A. M., Abramson, L. Y., Vohs, K. D., \& Joiner, T. E. (2008). Refining the relationships of perfectionism, self-efficacy, and stress to dieting and binge eating: Examining the appearance, interpersonal, and academic domains. International Journal of Eating Disorders, 41(8), 713-721. https://doi.org/10. 1002/eat.20563.

Choo, S. Y., \& Chan, C. K. Y. (2013). Predicting eating problems among Malaysian Chinese: Differential roles of positive and negative perfectionism. Personality and Individual Differences, 54(6), 744-749. https://doi.org/10.1016/j.paid.2012.11.036.

Cooley, E., \& Toray, T. (2001). Disordered eating in college freshman women: A prospective study. Journal of American College Health, 49(5), 229-235. https://doi.org/10.1080/07448480109596308.

Crocker, J., \& Knight, K. M. (2005). Contingencies of self-worth. Current Directions in Psychological Science, 14(4), 200-203. https://doi.org/10.1037//0033-295X.108.3.593.

Crocker, J., Luhtanen, R. K., Cooper, M. L., \& Bouvrette, A. (2003). Contingencies of self-worth in college students: Theory and measurement. Journal of Personality and Social Psychology, 85(5), 894-908. https://doi.org/10.1037/0022-3514.85.5.894. 
Crow, S., Eisenberg, M. E., Story, M., \& Neumark-Sztainer, D. (2006). Psychosocial and behavioral correlates of dieting among overweight and non-overweight adolescents. Journal of Adolescent Health, 38(5), 569-574. https://doi.org/10.1016/j.jadohealth.2005.05.019.

Dalley, S. E., \& Buunk, A. P. (2011). The motivation to diet in young women: Fear is stronger than hope. European Journal of Social Psychology, 41(5), 672-680. https://doi.org/10.1002/ejsp.816.

Dour, H. J., \& Theran, S. A. (2011). The interaction between the superhero ideal and maladaptive perfectionism as predictors of unhealthy eating attitudes and body esteem. Body Image, 8(1), 93-96. https:// doi.org/10.1016/j.bodyim.2010.10.005.

Downey, C. A., Reinking, K. R., Gibson, J. M., Cloud, J. A., \& Chang, E. C. (2014). Perfectionistic cognitions and eating disturbance: Distinct mediational models for males and females. Eating Behaviors, 15(3), 419-426. https://doi.org/10.1016/j.eatbeh.2014.04.020.

Drewnowski, A., Yee, D. K., Kurth, C. L., \& Krahn, D. D. (1994). Eating pathology and DSM-III-R bulimia nervosa: A continuum of behavior. The American Journal of Psychiatry, 151(8), 1217-1219. https://doi.org/10.1176/ajp.151.8.1217.

Dunn, J. G. H., Gotwals, J. K., \& Dunn, J. C. (2005). An examination of the domain specificity of perfectionism among intercollegiate student-athletes. Personality and Individual Differences, 38(6), 14391448. https://doi.org/10.1016/j.paid.2004.09.009.

Dwyer, J. T., Feldman, J. J., \& Mayer, J. (1970). The social psychology of dieting. Journal of Health and Social Behavior, 11(4), 269-287. https://doi.org/10.2307/2948575.

Egan, S. J., Wade, T. D., \& Shafran, R. (2011). Perfectionism as a transdiagnostic process: A clinical review. Clinical Psychology Review, 31(2), 203-212. https://doi.org/10.1016/j.cpr.2010.04.009.

Elliot, A. J. (2008). Approach and avoidance motivation. In A. J. Elliot (Ed.), Handbook of approach and avoidance motivation (pp. 3-14). New York, NY: Psychology Press. https://doi.org/10.4324/ 9780203888148

Enns, M. W., \& Cox, B. J. (2002). The nature and assessment of perfectionism: A critical analysis. In G. L. Flett \& P. L. Hewitt (Eds.), Perfectionism: Theory, research, and treatment (pp. 33-62). Washington, DC: American Psychological Association. https://doi. org/10.1037/10458-002.

Esposito, R. M., Stoeber, J., Damian, L. E., Alessandri, G., \& Lombardo, C. (2019). Eating disorder symptoms and the $2 \times 2$ model of perfectionism: Mixed perfectionism is the most maladaptive combination. Eating and Weight Disorders, 24(4), 749-755. https://doi.org/ 10.1007/s40519-017-0438-1.

Fairburn, C. G., Shafran, R., \& Cooper, Z. (1999). A cognitive behavioural theory of anorexia nervosa. Behaviour Research and Therapy, 37(1), 1-13. https://doi.org/10.1016/S0005-7967(98) 00102-8.

Fairburn, C. G., Cooper, Z., \& Shafran, R. (2003). Cognitive behaviour therapy for eating disorders: A "transdiagnostic" theory and treatment. Behaviour Research and Therapy, 41(5), 509-528. https:// doi.org/10.1016/S0005-7967(02)00088-8.

Farstad, S. M., McGeown, L. M., \& Von Ranson, K. M. (2016). Eating disorders and personality, 2004-2016: A systematic review and meta-analysis. Clinical Psychology Review, 46, 91-105. https://doi.org/ 10.1016/j.cpr.2016.04.005.

Fitzgibbon, M. L., Sánchez-Johnsen, L. A. P., \& Martinovich, Z. (2003). A test of the continuity perspective across bulimic and binge eating pathology. International Journal of Eating Disorders, 34(1), 83-97. https://doi.org/10.1002/eat.10160.

Frost, R. O., Marten, P., Lahart, C., \& Rosenblate, R. (1990). The dimensions of perfectionism. Cognitive Therapy and Research, 14(5), 449-468. https://doi.org/10.1007/BF01172967.

Garner, D. M., Olmsted, M. P., Bohr, Y., \& Garfinkel, P. E. (1982). The Eating Attitudes Test: Psychometric features and clinical correlates. Psychological Medicine, 12(4), 871-878. https://doi.org/10.1017/ s0033291700049163.
Gilman, R., \& Ashby, J. S. (2003). Multidimensional perfectionism in a sample of middle school students: An exploratory investigation. Psychology in the Schools, 40(6), 677-689. https://doi.org/10. 1002/pits.10125.

Haase, A. M., Prapavessis, H., \& Owens, R. G. (2002). Perfectionism, social physique anxiety and disordered eating: A comparison of male and female elite athletes. Psychology of Sport and Exercise, 3(3), 209-222. https://doi.org/10.1016/S1469-0292(01)00018-8.

Haase, A. M., Prapavessis, H., \& Owens, R. G. (2013). Domainspecificity in perfectionism: Variations across domains of life. Personality and Individual Differences, 55(6), 711-715. https:// doi.org/10.1016/j.paid.2013.05.025.

Haynos, A. F., Utzinger, L. M., Lavender, J. M., Crosby, R. D., Cao, L., Peterson, C. B., Crow, S. J., Wonderlich, S. A., Engel, S. G., Mitchell, J. E., Le Grange, D., \& Goldschmidt, A. B. (2018a). Subtypes of adaptive and maladaptive perfectionism in anorexia nervosa. Journal of Psychopathology and Behavioral Assessment, 40, 691-700. https://doi.org/10.1007/s10862-018-9672-8.

Haynos, A. F., Wang, S. B., \& Fruzzetti, A. E. (2018b). Restrictive eating is associated with emotion regulation difficulties in a non-clinical sample. Eating Disorders, 26(1), 5-12. https://doi.org/10.1002/cncr. 27633.Percutaneous.

Heatherton, T. E., \& Baumeister, R. F. (1991). Binge eating as escape from self-awareness. Psychological Bulletin, 110(1), 86-108. https://doi.org/10.1037/00332909.110.1.86.

Hetherington, M. M., \& Burnett, L. (1994). Ageing and the pursuit of slimness: Dietary restraint and weight satisfaction in elderly women. British Journal of Clinical Psychology, 33(3), 391-400. https://doi. org/10.1111/j.2044-8260.1994.tb01135.x.

Hewitt, P. L., \& Flett, G. L. (1991). Perfectionism in the self and social contexts: Conceptualization, assessment, and association with psychopathology. Journal of Personality and Social Psychology, 60(3), 456-470. https://doi.org/10.1037/0022-3514.60.3.456.

Hewitt, P. L., Flett, G., \& Ediger, E. (1995). Perfectionism traits and perfectionistic self- presentation in eating disorder attitudes, characteristics, and symptoms. International Journal of Eating Disorders, 18(4), 317-326. https://doi.org/10.1002/1098-108x(199512)18: 4<317::AID-EAT2260180404>3.0.co;2-2.

Holston, J. I., \& Cashwell, C. S. (2000). Family functioning and eating disorders among college women: A model of prediction. Journal of College Counseling, 3, 5-16. https://doi.org/10.1002/j.2161-1882. 2000.tb00159.x.

Hunthausen, J. M., Truxillo, D. M., Bauer, T. N., \& Hammer, L. B. (2003). A field study of frame-of-reference effects on personality test validity. Journal of Applied Psychology, 88(3), 545-551. https://doi.org/10.1037/0021-9010.88.3.545.

Jacobi, C., Hayward, C., de Zwaan, M., Kraemer, H. C., \& Agras, W. S. (2004). Coming to terms with risk factors for eating disorders: Application of risk terminology and suggestions for a general taxonomy. Psychological Bulletin, 130(1), 19-65. https://doi.org/10. 1037/0033-2909.130.1.19.

Joyce, F., Watson, H. J., Egan, S. J., \& Kane, R. T. (2012). Mediators between perfectionism and eating disorder psychopathology in a community sample. Eating Behaviors, 13(4), 361-365. https://doi. org/10.1016/j.eatbeh.2012.07.002.

Keel, P. K., Heatherton, T. F., Baxter, M. G., \& Joiner, T. E. (2007). A 20-year longitudinal study of body weight, dieting, and eating disorder symptoms. Journal of Abnormal Psychology, 116(2), 422432. https://doi.org/10.1037/0021-843X.106.1.117.

Krahn, D. D., Kurth, C. L., Gomberg, E., \& Drewnowski, A. (2005). Pathological dieting and alcohol use in college women-A continuum of behaviors. Eating Behaviors, 6, 43-52. https://doi.org/10.1016/j. eatbeh.2004.08.004.

Lethbridge, J., Watson, H. J., Egan, S. J., Street, H., \& Nathan, P. R. (2011). The role of perfectionism, dichotomous thinking, shape and weight overvaluation, and conditional goal setting in eating 
disorders. Eating Behaviors, 12(3), 200-206. https://doi.org/10. 1016/j.eatbeh.2011.04.003.

Levine, S. L., \& Milyavskaya, M. (2018). Domain-specific perfectionism: An examination of perfectionism beyond the trait-level and its link to well-being. Journal of Research in Personality, 74, 56-65. https://doi.org/10.1016/j.jrp.2018.02.002.

Liechty, J. M., \& Lee, M. J. (2013). Longitudinal predictors of dieting and disordered eating among young adults in the U.S. International Journal of Eating Disorders, 46(8), 790-800. https://doi.org/10. 1002/eat.22174.

Luo, J., Forbush, K. T., Williamson, J. A., Markon, K. E., \& Pollack, L. O. (2013). How specific are the relationships between eating disorder behaviors and perfectionism? Eating Behaviors, 14(3), 291924. https://doi.org/10.1016/j.eatbeh.2013.04.003.

Macedo, A., Soares, M. J., Azevedo, M. H., Gomes, A., Pereira, A. T., Maia, B., \& Pato, M. (2007). Perfectionism and eating attitudes in Portuguese university students. European Eating Disorders Review, 15, 296-304. https://doi.org/10.1002/erv.735.

Mangweth-Matzek, B., Rupp, C. I., Hausmann, A., Assmayr, K., Mariacher, E., Kemmler, G., Whitworth, A. B., \& Biebl, W. (2006). Never too old for eating disorders or body dissatisfaction: A community study of elderly women. International Journal of Eating Disorders, 39(7), 583-586. https://doi.org/10.1002/eat.

Martinsen, M., Bratland-Sanda, S., Eriksson, A. K., \& Sundgot-Borgen, J. (2010). Dieting to win or to be thin? A study of dieting and disordered eating among adolescent elite athletes and non-athlete controls. British Journal of Sports Medicine, 44(1), 70-76. https:// doi.org/10.1136/bjsm.2009.068668.

Midlarsky, E., \& Nitzburg, G. (2008). Eating disorders in middle-aged women. Journal of General Psychology, 135(4), 393-408. https:// doi.org/10.3200/GENP.135.4.393-408.

Midlarsky, E., Marotta, A. K., Pirutinsky, S., Morin, R. T., \& McGowan, J. C. (2018). Psychological predictors of eating pathology in older adult women. Journal of Women and Aging, 30(2), 145-157. https:// doi.org/10.1080/08952841.2017.1295665.

Mitchelson, J. K. (2009). Seeking the perfect balance: Perfectionism and work-family conflict. Journal of Occupational and Organizational Psychology, 82(2), 349-367. https://doi.org/10.1348/ $096317908 X 314874$

Mitzman, S. F., Slade, P., \& Dewey, M. E. (1994). Preliminary development of a questionnaire designed to measure neurotic perfectionism in the eating disorders. Journal of Clinical Psychology, 50(4), 516522. https://doi.org/10.1002/1097-4679(199407)50:4<516::AIDJCLP2270500406>3.0.CO;2-0.

Murphy, R., Straebler, S., Cooper, Z., \& Fairburn, C. G. (2010). Cognitive behavioral therapy for eating disorders. Psychiatric Clinics of North America, 33, 611-627. https://doi.org/10.1016/j. psc.2010.04.004

Muyan, M., Chang, E. C., Jilani, Z., \& Yu, T. (2015). Predicting eating disturbances in Turkish adult females: Examining the role of intimate partner violence and perfectionism. Eating Behaviors, 19 , 102-105. https://doi.org/10.1016/j.eatbeh.2015.07.004.

Neumark-Sztainer, D., Wall, M., Guo, J., Story, M., Haines, J., \& Eisenberg, M. (2006). Obesity, disordered eating, and eating disorders in a longitudinal study of adolescents: How do dieters fare 5 years later? Journal of the American Dietetic Association, 106(4), 559-568. https://doi.org/10.1016/j.jada.2006.01.003.

Nevonen, L., \& Broberg, A. G. (2000). The emergence of eating disorders: An exploratory study. European Eating Disorders Review, 8(4), 279-292. https://doi.org/10.1002/1099-0968(200008)8: 4<279::AID-ERV348>3.0.CO;2-J.

Pastor, D. A. (2010). Quantitative methods in the social and behavioral sciences: A guide for researchers and reviewers. In G. R. Hancock \& R. O. Mueller (Eds.), Cluster analysis (pp. 41-54). New York, NY: Taylor \& Francis.
Patterson, R. E., Wang, K. T., \& Slaney, R. B. (2012). Multidimensional perfectionism, depression and relational health in women with eating disturbances. Eating Behaviors, 13(3), 226-232. https://doi.org/ 10.1016/j.eatbeh.2012.03.004.

Paulson, L. R., \& Rutledge, P. C. (2014). Effects of perfectionism and exercise on disordered eating in college students. Eating Behaviors, 15(1), 116-119. https://doi.org/10.1016/j.eatbeh.2013.11.005.

Pearson, C. A., \& Gleaves, D. H. (2006). The multiple dimensions of perfectionism and their relation with eating disorder features. Personality and Individual Differences, 41(2), 225-235. https:// doi.org/10.1016/j.paid.2006.01.013.

Peck, L. D., \& Lightsey, O. R. (2008). The eating disorders continuum, self-esteem, and perfectionism. Journal of Counseling and Development, 86(2), 184-192. https://doi.org/10.1002/j.15566678.2008.tb00496.x.

Petersson, S., Johnsson, P., \& Perseius, K. I. (2017). A Sisyphean task: Experiences of perfectionism in patients with eating disorders. Journal of Eating Disorders, 5, Article 3. https://doi.org/10.1186/ s40337-017-0136-4.

Polivy, J., \& Herman, C. P. (1985). Dieting and binging: A causal analysis. American Psychologist, 40(2), 193-201. https://doi.org/10. 1037/0003-066X.40.2.193.

Quick, V. M., Byrd-Bredbenner, C., \& Neumark-Sztainer, D. (2013). Chronic illness and disordered eating: A discussion of the literature. Advances in Nutrition, 4, 277-286. https://doi.org/10.3945/an.112. 003608.277.

Rice, K. G., \& Ashby, J. S. (2007). An efficient method for classifying perfectionists. Journal of Counseling Psychology, 54(1), 72-85. https://doi.org/10.1037/0022-0167.54.1.72.

Rice, K. G., Ashby, J. S., \& Gilman, R. (2011). Classifying adolescent perfectionists. Psychological Assessment, 23(3), 563-577. https:// doi.org/10.1037/a0022482.

Rice, K. G., Richardson, C. M. E., \& Tueller, S. (2014). The short form of the Revised Almost Perfect Scale. Journal of Personality Assessment, 96(3), 368-379. https://doi.org/10.1080/00223891. 2013.838172.

Rojo, L., Livianos, L., Conesa, L., García, A., Domínguez, A., Rodrigo, G., Sanjuán, L., \& Vila, M. (2003). Epidemiology and risk factors of eating disorders: A two-stage epidemiologic study in a Spanish population aged 12-18 years. The International Journal of Eating Disorders, 34, 281-291. https://doi.org/10.1002/eat.10179.

Schmidt, U., \& Treasure, J. (2006). Anorexia nervosa: Valued and visible. A cognitive-interpersonal maintenance model and its implications for research and practice. British Journal of Clinical Psychology, 45(3), 343-366. https://doi.org/10.1348/ $014466505 X 53902$.

Shafran, R., \& Mansell, W. (2001). Perfectionism and psychopathology: A review of research and treatment. Clinical Psychology Review, 21(6), 879-906. https://doi.org/10.1016/S0272-7358(00)00072-6.

Shafran, R., Cooper, Z., \& Fairburn, C. G. (2002). Clinical perfectionism: A cognitive-behavioural analysis. Behaviour Research and Therapy, 40(7), 773-791. https://doi.org/10.1016/S0005-7967(01) 00059-6.

Shafran, R., Lee, M., Payne, E., \& Fairburn, C. G. (2006). The impact of manipulating personal standards on eating attitudes and behaviour. Behaviour Research and Therapy, 44, 911-920. https://doi.org/10. 1016/j.brat.2005.08.009.

Sherry, S. B., Hewitt, P. L., Besser, A., McGee, B. J., \& Flett, G. L. (2004). Self-oriented and socially prescribed perfectionism in the Eating Disorder Inventory perfectionism subscale. International Journal of Eating Disorders, 35(1), 69-79. https://doi.org/10. 1002/eat.10237.

Sherry, S. B., Hewitt, P. L., Flett, G. L., Lee-Baggley, D. L., \& Hall, P. A. (2007). Trait perfectionism and perfectionistic self-presentation in personality pathology. Personality and Individual Differences, 42(3), 477-490. https://doi.org/10.1016/j.paid.2006.07.026. 
Sherry, S. B., Vriend, J. L., Hewitt, P. L., Sherry, D. L., Flett, G. L., \& Wardrop, A. A. (2009). Perfectionism dimensions, appearance schemas, and body image disturbance in community members and university students. Body Image, 6(2), 83-89. https://doi.org/10. 1016/j.bodyim.2008.12.002.

Shisslak, C. M., Crago, M., \& Estes, L. S. (1995). The spectrum of eating disturbances. International Journal of Eating Disorders, 18(3), 209-219. https://doi.org/10.1002/1098-108X(199511)18:3<209:: AID-EAT2260180303>3.0.CO;2-E.

Slade, P. (1982). Towards a functional analysis of anorexia nervosa and bulimia nervosa. British Journal of Clinical Psychology, 21, 167179. https://doi.org/10.1111/j.2044-8260.1982.tb00549.x.

Slaney, R., Rice, K., Mobley, M., Trippi, J., \& Ashby, J. S. (2001). The Revised Almost Perfect Scale. Measurement and Evaluation in Counseling \& Development, 34(3), 130-145. https://doi.org/10. 1080/07481756.2002.12069030.

Slof-Op't Landt, M. C. T., Claes, L., \& van Furth, E. F. (2016). Classifying eating disorders based on "healthy" and "unhealthy" perfectionism and impulsivity. International Journal of Eating Disorders, 49(7), 673-680. https://doi.org/10.1002/eat.22557.

Slof-Op't Landt, M. C. T., van Furth, E. F., van Beijsterveldt, C. E. M., Bartels, M., Willemsen, G., de Geus, E. J., Ligthart, L., \& Boomsma, D. I. (2017). Prevalence of dieting and fear of weight gain across ages: A community sample from adolescents to the elderly. International Journal of Public Health, 62(8), 911-919. https://doi.org/10.1007/s00038-017-0948-7.

Soenens, B., Vansteenkiste, M., Vandereycken, W., Luyten, P., Sierens, E., \& Goossens, L. (2008). Perceived parental psychological control and eating-disordered symptoms. The Journal of Nervous and Mental Disease, 196(2), 144-152. https://doi.org/10.1097/NMD. 0b013e318162aabf.

Stice, E. (2002). Risk and maintenance factors for eating pathology: A meta-analytic review. Psychological Bulletin, 128(5), 825-848. https://doi.org/10.1037/0033-2909.128.5.825.

Stice, E., Ng, J., \& Shaw, H. (2010). Risk factors and prodromal eating pathology. Journal of Child Psychology and Psychiatry, and Allied Disciplines, 51(4), 518-525. https://doi.org/10.1111/j.1469-7610. 2010.02212.x.

Stice, E., Marti, C. N., \& Durant, S. (2011). Risk factors for onset of eating disorders: Evidence of multiple risk pathways from an 8year prospective study. Behaviour Research and Therapy, 49(10), 622-627. https://doi.org/10.1016/j.brat.2011.06.009.
Stoeber, J., \& Stoeber, F. S. (2009). Domains of perfectionism: Prevalence and relationships with perfectionism, gender, age, and satisfaction with life. Personality and Individual Differences, 46(4), 530-535. https://doi.org/10.1016/j.paid.2008.12.006.

Stoeber, J., \& Yang, H. (2015). Physical appearance perfectionism explains variance in eating disorder symptoms above general perfectionism. Personality and Individual Differences, 86, 303-307. https://doi.org/10.1016/j.paid.2015.06.032.

Stoeber, J., Madigan, D. J., Damian, L. E., Esposito, R. M., \& Lombardo, C. (2017). Perfectionism and eating disorder symptoms in female university students: The central role of perfectionistic self-presentation. Eating and Weight Disorders, 22(4), 641-648. https://doi.org/ 10.1007/s40519-016-0297-1.

Stumpf, H., \& Parker, W. D. (2000). A hierarchical structural analysis of perfectionism and its relation to other personality characteristics. Personality and Individual Differences, 28(5), 837-852. https:// doi.org/10.1016/S0191-8869(99)00141-5.

Terry-Short, L. A., Owens, R. G., Slade, P. D., \& Dewey, M. E. (1995). Positive and negative perfectionism. Personality and Individual Differences, 18(5), 663-668. https://doi.org/10.1016/01918869(94)00192-U.

Thompson, K, A., \& Bardone-Cone, A, M. (2019). Disordered eating behaviors and attitudes and their correlates among a community sample of older women. Eating Behaviors, 34. https://doi.org/10. 1016/j.eatbeh.2019.05.004

Verstuyf, J., Patrick, H., Vansteenkiste, M., \& Teixeira, P. J. (2012). Motivational dynamics of eating regulation: A self-determination theory perspective. International Journal of Behavioral Nutrition and Physical Activity, 9, Article 21. https://doi.org/10.1186/14795868-9-21.

Welch, E., Miller, J. L., Ghaderi, A., \& Vaillancourt, T. (2009). Does perfectionism mediate or moderate the relation between body dissatisfaction and disordered eating attitudes and behaviors? Eating Behaviors, 10(3), 168-175. https://doi.org/10.1016/j.eatbeh.2009. 05.002 .

Yang, H., \& Stoeber, J. (2012). The Physical Appearance Perfectionism Scale: Development and preliminary validation. Journal of Psychopathology and Behavioral Assessment, 34(1), 69-83. https://doi.org/10.1007/s10862-011-9260-7.

Publisher's Note Springer Nature remains neutral with regard to jurisdictional claims in published maps and institutional affiliations. 